Military Technical College Kobry El-Kobbah, Cairo, Egypt

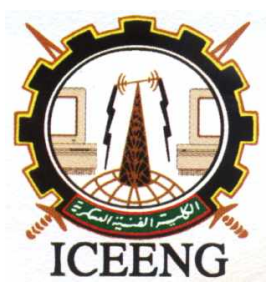

\author{
$6^{\text {th }}$ International Conference \\ on Electrical Engineering \\ ICEENG 2008
}

\title{
Expert system for the load management, unit commitment and optimised scheduling of power generation at hydel power plants
}

$$
\text { By }
$$

\author{
Syed Abdul Rahman Kashif*
}

\author{
Muhammad Asghar Saqib**
}

\section{Abstract:}

This paper presents an artificial intelligence based inference system for economic load management and scheduling of power generation. A database is developed in which the whole record of the behavior of a plant, in different situations, is available. The decisions of experts are also fed in the knowledge base. Rule base is developed on the basis of experts decisions, different conditions of load demands, unit commitment and power controlling factors such as discharge rate of water, velocity of water flow, head of water available, requirement of water for irrigation purposes and machines specifications. Then the inferences engine under different conditions fires the appropriate rules from the rule base and controls all the above-mentioned parameters. It also makes decisions to select the optimised machines for power generation to meet the peak and base load power demands. This expert system is developed in Prolog. Simulation results using the data of Mangla Power Station were compared with the actual results of the plant for this purpose and found satisfactory.

\section{Keywords:}

Expert system, knowledge base, rule base, rule adjuster, inference engine, data processor, unit commitment, load management and Prolog.

* Lecturer, Department of Electrical Engineering, UET, Lahore 54890, Pakistan

** Associate Professor, Department of Electrical Engineering, UET, Lahore 54890, Pakistan 


\section{Introduction:}

The economic load management and power generation are the core requirements in this era when the world is facing energy crisis. 'Expert Systems (ES)' are being used nowadays for decision managements as they use high-speed computers to solve real-life problems [1]-[3]. Decision-analysis process, depending upon modeling, can solve complex problems. An expert system uses the relationships between operation research, decision-support systems, heuristic programming and artificial intelligence to make a decision. Database related to a particular problem may save the experience of experts in that domain which may be called in any situation for analysis and diagnosis. Load management, unit commitment and generation can be controlled by the expert system which makes appropriate decision using spread sheets, data bases, statistical analysis, simulation results and linear programming [4]-[5].

This paper presents an artificial intelligence based inference system for energy management. A database is developed, in which the whole record of the behavior of a plant in different situations is available. The decisions of experts are also fed in the knowledge base. 'Rule Base' is developed on the basis of experts decisions, different conditions of load demands, unit commitment and power controlling factors such as discharge rate of water, velocity of water flow, head of water available, requirement of water for irrigation purposes and machines specifications. Then the inference engine under different conditions fires appropriate rules from the rule base and controls all the above mentioned parameters. It also makes decisions to select the optimised machines for power generation to meet the peak and base load power demands.

This expert system is developed in Prolog. Results using the data of Mangla Power Plant were compared with the software for this purpose and found satisfactory. The expert system with all above features is most economical solution to meet the energy crisis by controlling the load management, schedules and power generation.

\section{Artificial Intelligence and expert system.:}

In 'Artificial Intelligence (AI)' is that every aspect of learning or any other feature of human intelligence can be so precisely described that a machine can be made to simulate it [6]. Expert system - which basically consists of inference engine, knowledge base, working memory, database, data-processing analytical methods, rule adjuster and an interface for knowledge engineer and user - is a sub category of AI. Knowledge base being the heart of ES has facts and rules. In our implementation data regarding all generators and turbine units in Mangla Power Station, water level available, flow rate of water and velocity are treated as facts. The rules which represent the heuristic relations 
are fed in the data base by knowledge engineer or domain experts and control the operation of unit commitment, optimised scheduling of power generation based upon mathematical operations. Inference engine examines the status of knowledge base and working memory, and determines which facts are known and can also add new facts available in knowledge base. New facts are developed by the inference process, which are also stored in working memory while rule adjuster checks the rules for consistency and completeness and can revise the knowledge base. Interface handles the inputs through different sensors and the actuator operates according to the decisions of ES. Fig. 1 shows the typical architecture of the expert system used while Table 1 shows the data of Mangla Power Station i.e., capacity per machine against reservoir level which were used to develop the rule base and facts. Other data gained from experienced engineers were used to make heuristics, which sometimes make decision process easier for the expert system. Cost curves of the units were also fed in knowledge base for optimized operation and control of the system.

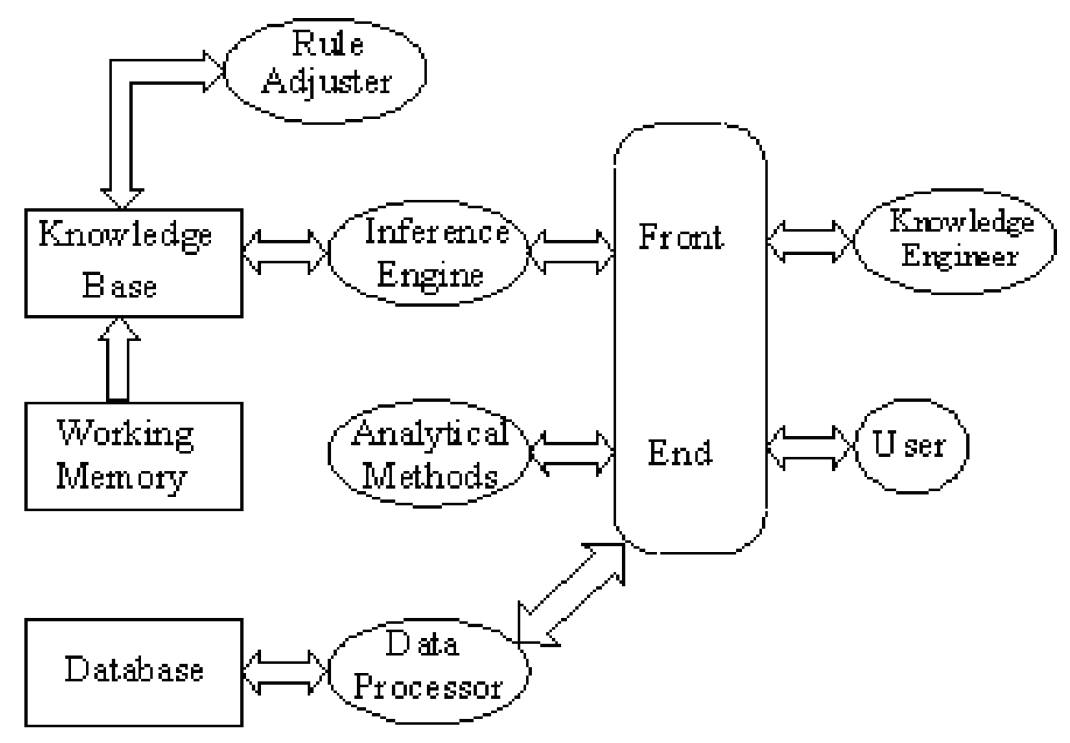

Figure (1): Architecture of the used expert system

\section{Load Management and unit commitment:}

'Unit Commitment' means to decide about how many machines will run to fulfill the load requirement in an economical way under certain constraints [7]. For k number of machines there will be $2^{\mathrm{k}}-1$ combinations in which machines can run. Expert system first of all decides how many machines will run to meet load requirement with present head available and the rate of discharge of water. For this, different combinations are tested to economize the power generation. Then, according to specifications, load is 
distributed among the combination of machines selected. The complete algorithm used is shown in the form of a flowchart in Fig. 2. Expert system makes decisions on the basis of facts and rules in its knowledge base. If the load, considered for the reliable system design changes in some specified range, then ES varies power generation from a certain unit such that the overall generation cost remains economical. Data base of the expert system was developed by the facts derived from the data provided by Mangla Power Station as shown in Table 1. During implementation, a number of constraints were considered. Local constraints considered are minimum and maximum load handling capability of a unit, minimum up and down time, hot and cold cost, hot and cold start, unit initial conditions, unit status restriction and unit ramp rate. Constraints on plant crew, stability, security, station and spinning reserve were also considered.

\section{Table (1): Mangla Power Station' capacity per machine against reservoir level}

\begin{tabular}{|c|c|c|c|c|c|c|c|c|c|}
\hline \multirow{2}{*}{$\begin{array}{c}\text { Sr. } \\
\#\end{array}$} & \multirow{2}{*}{$\begin{array}{l}\text { HRL } \\
\text { SPD } \\
(\mathrm{ft})\end{array}$} & \multirow{2}{*}{$\begin{array}{c}\text { Net } \\
\text { Head } \\
(\mathrm{ft})\end{array}$} & \multicolumn{4}{|c|}{ Units Capacity in MW } & \multirow{2}{*}{$\begin{array}{c}\text { Total } \\
\text { Capacity } \\
\text { in MW }\end{array}$} & \multirow{2}{*}{$\begin{array}{c}\text { Discharge } \\
\text { per MW } \\
\text { (CFS) }\end{array}$} & \multirow{2}{*}{$\begin{array}{c}\text { Total } \\
\text { Discharge } \\
\text { (CFS) }\end{array}$} \\
\hline & & & $\begin{array}{c}\text { Machine } \\
1-4\end{array}$ & $\begin{array}{c}\text { Machine } \\
5-6\end{array}$ & $\begin{array}{c}\text { Machine } \\
7-8\end{array}$ & $\begin{array}{c}\text { Machine } \\
9-10\end{array}$ & & & \\
\hline 1 & 1050 & 207 & 54 & 55 & 54 & 55 & 544 & 65 & 35360 \\
\hline 2 & 1055 & 212 & 57 & 60 & 60 & 60 & 588 & 64 & 37632 \\
\hline 3 & 1060 & 217 & 58 & 60 & 60 & 60 & 592 & 64 & 37883 \\
\hline 4 & 1065 & 222 & 61 & 64 & 64 & 64 & 628 & 62 & 38936 \\
\hline 5 & 1070 & 227 & 66 & 69 & 68 & 69 & 676 & 6 & 40560 \\
\hline 6 & 1075 & 232 & 68 & 70 & 69 & 70 & 690 & 59 & 40710 \\
\hline 7 & 1080 & 237 & 69 & 71 & 70 & 71 & 700 & 58 & 40600 \\
\hline 8 & 1085 & 242 & 71 & 72 & 71 & 72 & 714 & 57 & 40698 \\
\hline 9 & 1090 & 247 & 75 & 75 & 73 & 75 & 746 & 55 & 41030 \\
\hline 10 & 1095 & 252 & 77 & 78 & 76 & 78 & 772 & 55 & 42460 \\
\hline 11 & 1100 & 257 & 80 & 81 & 80 & 81 & 804 & 54 & 43416 \\
\hline 12 & 1105 & 262 & 82 & 84 & 82 & 84 & 828 & 52 & 43056 \\
\hline 13 & 1110 & 267 & 84 & 87 & 83 & 87 & 850 & 50 & 42500 \\
\hline 14 & 1115 & 272 & 86 & 91 & 84 & 91 & 876 & 49 & 42924 \\
\hline 15 & 1120 & 277 & 88 & 94 & 86 & 94 & 908 & 45 & 40860 \\
\hline 16 & 1125 & 280 & 92 & 97 & 90 & 97 & 936 & 44 & 41184 \\
\hline 17 & 1130 & 282 & 94 & 101 & 93 & 101 & 966 & 44 & 42504 \\
\hline 18 & 1135 & 287 & 96 & 104 & 95 & 104 & 990 & 44 & 43560 \\
\hline 19 & 1140 & 292 & 99 & 108 & 97 & 108 & 1022 & 44 & 44968 \\
\hline 20 & 1145 & 296 & 102 & 110 & 102 & 110 & 1052 & 44 & 46288 \\
\hline 21 & 1150 & 297 & 104 & 112 & 104 & 112 & 1072 & 44 & 47168 \\
\hline 22 & 1155 & 302 & 107 & 115 & 107 & 115 & 1102 & 43 & 47386 \\
\hline 23 & 1160 & 309 & 110 & 117 & 108 & 117 & 1124 & 43 & 48332 \\
\hline 24 & 1165 & 312 & 113 & 12 & 110 & 120 & 1152 & 43 & 49535 \\
\hline 25 & 1169 & 317 & 115 & 125 & 115 & 125 & 1190 & 42 & 49980 \\
\hline 26 & 1170 & 322 & 115 & 125 & 115 & 125 & 1190 & 41 & 48790 \\
\hline 27 & 1175 & 327 & 115 & 125 & 115 & 125 & 1190 & 40 & 47600 \\
\hline 28 & 1180 & 332 & 115 & 125 & 115 & 125 & 1190 & 39 & 46410 \\
\hline 29 & 1185 & 337 & 115 & 125 & 115 & 125 & 1190 & 38 & 45220 \\
\hline 30 & 1190 & 342 & 115 & 125 & 115 & 125 & 1190 & 38 & 45220 \\
\hline 31 & 1195 & 347 & 115 & 125 & 115 & 125 & 1190 & 37 & 44030 \\
\hline 32 & 1200 & 352 & 115 & 125 & 115 & 125 & 1190 & 36 & 42840 \\
\hline
\end{tabular}




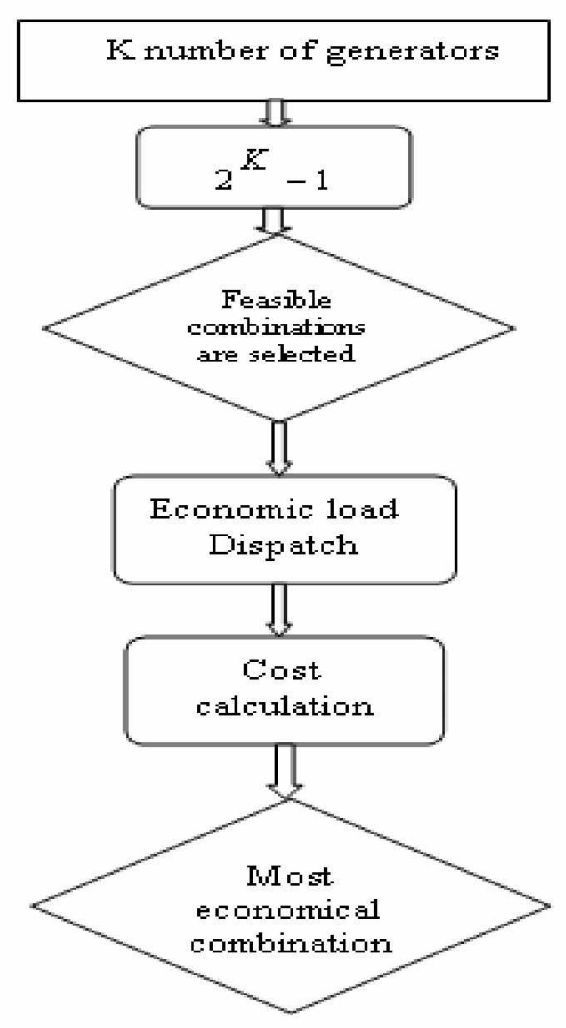

Figure (2): Flow chart of algorithm used in unit commitment

\section{Simulation results:}

The expert system was implemented using Prolog and was tested for number of different conditions under different load demands and gave the satisfactory results which are in correspondence to those which are acquired from the existing system of Mangla Power Station. Simulation was tested with the load demand from 500 MW to $1000 \mathrm{MW}$ under different head available and discharge rate of water. When the expert system was consulted for the economic demand of $630 \mathrm{MW}$ at the head of 278 feet, it committed 8 out of 10 units with the power distribution as given in Table 2, and these are accurate when compared to the data provided by Mangla Power Station.

Table (2): Results of load demand scheduling

\begin{tabular}{|c|c|c|c|c|c|c|c|c|}
\hline Machine no. & 1 & 2 & 3 & 4 & 5 & 8 & 9 & 10 \\
\hline Power delivered in MW & 75 & 78.5 & 72 & 70.5 & 75 & 86 & 88 & 85 \\
\hline
\end{tabular}




\section{Conclusions:}

The expert system presented in the paper can effectively control the operation of power plant by making decisions for unit commitment, load management and optimized power generation. Instead of so much calculations of general procedure adopted for this purpose expert system on the bases of rules and facts and previous decisions of expert in this domain, from the knowledge base, can optimize the performance of a hydral power plant. Decision making ability of ES enhances the performance of the system and reduces the time as taken by other software for the calculation using iterative procedure. The proposed ES is cost and time effective solution for the management of power generation scheduling and for unit commitment. It has shown competitive results in simulations in different consultation sessions under different load demand, head and water level conditions.

\section{References:}

[1] M.W. Firebaugh, Artificial Intelligence, Boyd and Fracer, Boston, 1988.

[2] N.C. Rowe, Artificial Intelligence through Prolog, Parentice-Hall, 1988.

[3] R.G Vedder, PC based expert system shells: Some desirable and less desirable characteristics, Expert System, Vol. 6, pp. 28-42, Feb. 1989.

[4] S.M. Chhaya and B.K. Bose, Expert system aided automated design, simulation and controller tunning of $A C$ drive system, IEEE IECON Conf. Rec., pp. 712-718, 1995.

[5] P. Ansarimehr, S. Barghinia and N. Vafadar, Short term load forecasting for Iran national power system using neural network and fuzzy expert system, IEEE, pp. 1082-1085, July 2002.

[6] T. Senjyu, P. Mandal and K. Uezato, Next day load curve forecasting using recurrent neural network structure, IEEE Trans. on Power Distribution System, pp. 388-394, March 2003.

[7] T. Saksornchai, W.J. Lee, M. Methaprayoon and J. Liao, Improve the unit commitment scheduling by using the neural network based short term load forecasting, IEEE Trans. Power Delivery, pp. 33-39, June 2004. 


\section{Biographies:}

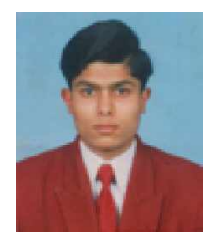

Syed Abdul Rahman Kashif was born in Lahore on 12 April 1983. He graduated in electrical engineering from the University of Engineering and Technology, Lahore, Pakistan in 2005. He joined the Department of Electrical Engineering at the University of Engineering and Technology, Lahore, in 2006 and is now a Lecturer in the Department. He is also studying, in the same Department, for his Masters degree. His areas of interest include Power Electronics, Application of Artificial Intelligence and Expert Systems in Power Systems, and Power System Protection.

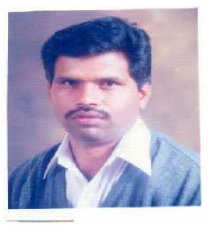

M.A. Saqib graduated in electrical power engineering from the Department of Electrical Engineering at the University of Engineering and Technology, Lahore (Pakistan), in 1991. He obtained his Masters and $\mathrm{PhD}$ degrees in electrical power engineering from University of Sydney, Australia, in 1996 and 1999 respectively. He then joined the Faculty of Electronics Engineering at GIK Institute, Topi (Pakistan), as Assistant Professor and became Associate Professor and Dean of the Faculty in 2005. He is now working as Associate Professor in the Department of Electrical Engineering at University of Engineering and Technology, Lahore. He research interests include Electrical Drives, Power Electronics, Electrical Arcs and Power System Protection. 